\title{
How Lucrative \& Challenging the Boundary less Opportunities for Data Scientists?
}

\author{
Sachin $\operatorname{Kumar}^{1}$ \& P. S. Aithal ${ }^{2}$ \\ ${ }^{1}$ Dept. of Computer Science, Hierank Business School, Noida, Uttar Pradesh, India \\ E-mail: sachinks.78@gmail.com \\ ${ }^{2}$ College of Business Management \& Commerce, Srinivas University, Mangalore, India \\ E-mail: psaithal@gmail.com
}

Area of the Paper: Information Technology.

Type of the Paper:Exploratory Study.

Type of Review: Peer Reviewed as per $|\mathrm{C}| \mathrm{O}|\mathrm{P}| \mathrm{E} \mid$ guidance.

Indexed In: OpenAIRE.

DOI: http://doi.org/10.5281/zenodo.3966222.

Google Scholar Citation: IJCSBE.

\section{How to Cite this Paper:}

Kumar, Sachin \& Aithal, P. S. (2020). How Lucrative \& Challenging the Boundary less Opportunities for Data Scientists?. International Journal of Case Studies in Business, IT, and Education (IJCSBE), 4(1), 223-236. DOI: http://doi.org/10.5281/zenodo.3966222.

International Journal of Case Studies in Business, IT and Education (IJCSBE)

A Refereed International Journal of Srinivas University, India.

(C) With Authors.

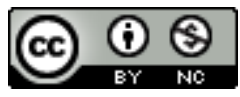

This work is licensed under a Creative Commons AttributionNon-Commercial 4.0 International License subject to proper citation to the publication source of the work.

Disclaimer: The scholarly papers as reviewed and published by the Srinivas Publications (S.P.), India are the views and opinions of their respective authors and are not the views or opinions of the S.P. The S.P. disclaims of any harm or loss caused due to the published content to any party. 


\title{
How Lucrative \& Challenging the Boundary less Opportunities for Data Scientists?
}

\author{
Sachin $\operatorname{Kumar}^{1}$ \& P. S. Aithal ${ }^{2}$ \\ ${ }^{1}$ Dept. of Computer Science, Hierank Business School, Noida, Uttar Pradesh, India \\ E-mail:sachinks.78@gmail.com \\ ${ }^{2}$ College of Business Management \& Commerce, Srinivas University, Mangalore, India \\ E-mail: psaithal@gmail.com
}

\begin{abstract}
The data scientist is a new profession which is considered as a key profession in the world of technologies and is one of the best paid jobs. A data scientist is a person who has developed expertise in the mathematical modelling and statistics that dominates programming and its different languages, computer science, and analytics. Data science comprises of data gathering, data warehousing, data analysis, data mining, online analytical processing, artificial intelligence, machine learning, and decision science for Predictive and prescriptive analytics for supporting managers for future decision process in a hectic competitive environment. Due to globalization and ICCT supported automation of many business processes, big data supported data science importance in many industries and hence Data scientists are also getting huge demand. Data scientists are key change-makers inside an enterprise that provides knowledge that they can illuminate the company's journey toward its ultimate business goals they have strong market demand. They are instrumental in inspiring both leaders and developers to build better products and paradigms. Their role in big business is becoming increasingly important, they are in ever shorter supply. Demand for data scientists is so exponentially growing that McKinsey expects a 50 percent difference in data scientists' supply versus demand by 2018. In this paper, we have analysed the continued opportunities for data scientists for 21st century business and how lucrative and challenging is their job based on opportunities and challenges framework.
\end{abstract}

Keywords: Data scientists, Data science, Big data, Lucrative salary jobs, Business analytics, Opportunities and challenges framework.

\section{INTRODUCTION:}

Data science is an interdisciplinary subject that leverages computational methods, processes, algorithms, and systems to extract knowledge and observations from both formal and unstructured knowledge. Data science is a part of computer science and is about data mining, deep learning and big data. Data science is an interdisciplinary area using scientific methods, processes, algorithms, and systems to draw knowledge and insights from both structural and unstructured information. Data science is a 'concept for unifying analytics, data analysis, machine learning and related approaches' to 'understanding and analysing actual phenomena' with data [1]. It employs techniques and theories derived from many fields in the context of mathematics, statistics, computer science and information science. Data Scientists not only conduct the exploratory analysis to discover insights from it but also uses several advanced machine learning algorithms to identify the future occurrence of a particular event. So, Data Science is mainly used to make decisions and forecasts using predictive causal analysis, prescriptive analytics (predictive plus science of decision-making), and machine learning. Business analytics refers to the skills, tools, methods for continuous iterative analysis and past company results from review to obtain insight and guide business planning. Market analytics focuses on gaining new perspectives and understanding based on data and statistical methods of business 
success [2-3]. Figure 1 lists some of the special knowledge and skill area required for the data scientist profession.

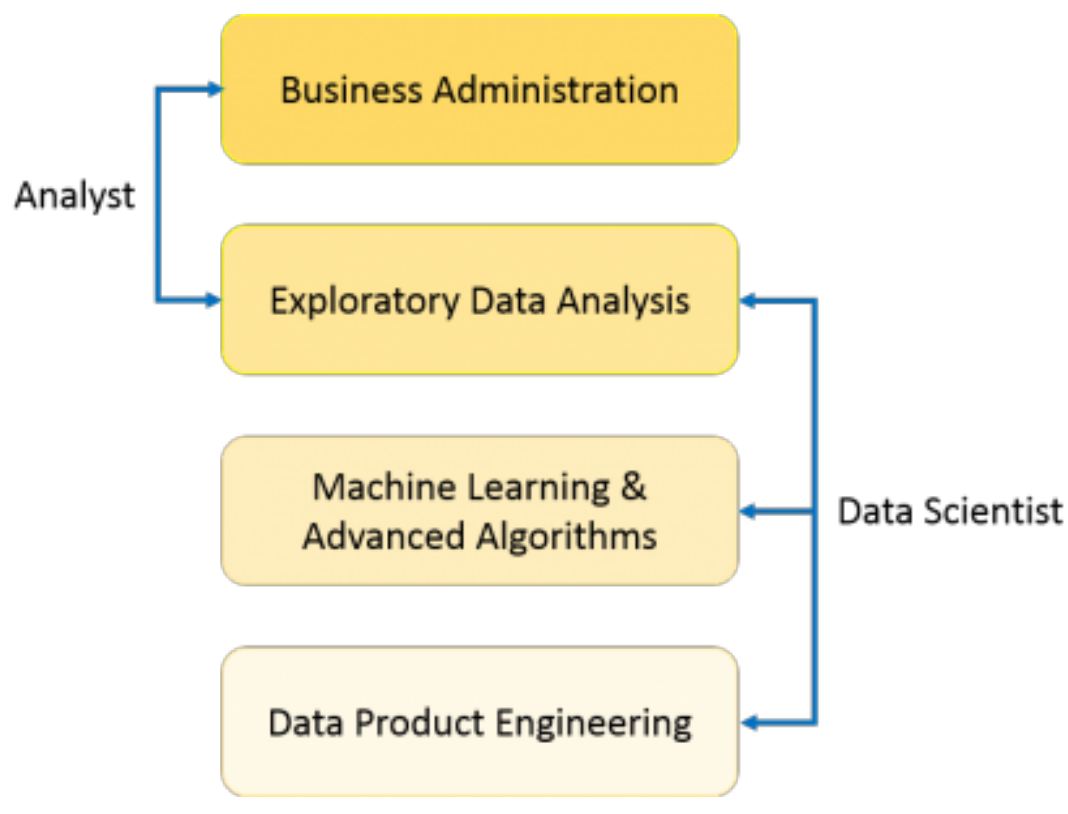

Fig. 1: Basic skills required for data scientists

Managers in organizations, by shaping and filtering data collected by their organizations, can make better decisions through better informed choices than in the past, with the help of data scientists of data science companies. Goals must be set clearly by the organizational managers before data scientists can theorize ways of achieving them. Good decision-making is crucial and can be achieved with the help of data scientists for companies and institutions to run efficiently and overcome unpredictable obstacles [3-4].

Some of the characteristics of data science involve:

1. Supporting and assisting business functions in better decision making, predicting, monitoring, assessing, and drawing insight into the market, future prediction of business growth.

2. Surveying and seeking solutions to societal issues used to boost marketing, attracting clients, innovating to enrich lives.

3. Acquire, process, clean, integrate, and store the data, initial data analysis, and analyse exploratory data. Use one or more algorithms and potentials. It needs a strong coder, too.

4. Apply different methods and techniques in data science such as machine learning, mathematical modelling, and artificial intelligence.

5. Measure and enhance stakeholder outcomes, and make feedback-based changes to replicate the cycle for solving a new question [3], [5].

\section{OBJECTIVES OF THE STUDY :}

The objectives of the paper include:

1.The importance of data science in organizational productivity.

2. The requirement for adopting data science as a profession in a career.

3. To know details on Data science \& related areas.

4. To explore how computer science and operations research techniques are integrated into data science.

5. To study the importance of data scientists in various industries through predictive analysis [6-7].

6. To analyse opportunities and challenges for data scientists.

7. Higher education in data science as specialization or super-specialization.

8. Demand versus Supply analysis of data scientists in India. 
9. Comparison of salary drawn by data scientists with ordinary software professionals in IT industry at entry level and at senior levels to know how lucrative the data science jobs.

\section{DATA SCIENCE IN ORGANIZATIONAL PRODUCTIVITY:}

Data science helps in various stages of planning, procurement, resource utilization, wastage management, supply and distribution processes by providing not only conventional data readily available in business processes but also to create new useful data for better decision making. Data creation and capture are moving data science beyond data analysis by adding data management processes including when and how data are collected, annotated, and organized. The winning organizations take advantage of data science to implement two universal improvement methods called real-time reporting and learning from historical data. Real time reporting makes customer interactions more effective by allowing services which can make customers to understand in a better way. Historic data allows interacting with better customers whereas real time reporting enhances customer interactions. Historic data allow how customer behaved in the past and allow to build predictive analytical models to learn they will likely behave in the future. To ensure improved productivity and efficiency, a data driven culture should be developed and adopted. The data driven culture should come from top executives of the organization and every manager at every level should know the data's inherent importance in their job role. It is proved that big data analytics of data science has an impact on eleven subdimensions of productivity of organization including planning, investment, coordination, control, connectivity, compatibility, modularity, technology, business knowledge, management knowledge, and relational knowledge [8-9].

\section{DATA SCIENCE AS A PROFESSION:}

Software scientists are not only responsible for market analytics, but they are also involved in the creation of data products and software applications, along with the development of visualizations and machine learning algorithms. Corporate analyst. Information administrator / analytics. Manager of business intelligence. Coding skills clubbed with mathematical expertise and the ability to objectively analyse form the arsenal of a good data scientist. Some of the in-demand data scientist skills that in data science would offer great career opportunities are:

- Languages to programming: $r$ / python / java

- Applied mathematics and statistics

- Hadoop and spark know-how working

- Sql and nosql databases

- Neural and machine learning networks

- Deep-learning skills: tensorflow, keras, pytorch.

- Awareness of creative thought \& the business [10-11].

\section{DATA SCIENCE \& RELATED AREAS :}

Data Science has various related areas such as Maths, Statistics, Machine Learning, Cluster Analysis, Data Mining, Big Data Analytics, Data Visualization, Artificial Intelligence, Neural Networks, Deep Learning, Deep Active Learning, and Cognitive Computing. Today in the digital world, data science is the buzzword. It integrates various disciplines, such as data analysis, machine learning, market analysis, cognitive computing, computer science, statistics, and so on.A Data Scientist's job description will be different in different organizations, depending on the organization 's priorities and the business line in which it is involved. Data science encapsulates fields which are numerous but related. Among the most famous of them are:

\section{Data Engineering}

Massive volumes of data are often managed by organizations. We need a professional who can easily manage this data and build solutions for data warehousing. It is the Data Engineer 's job that will be adept in languages such as SQL, Hive, Matlab, SAS, Python,Java, C++, etc.

\section{Data analysis}

Data analysis involves the retrieval and creation of meaningful information from sql or excel databases. A data analyst 's job is to mine primary and secondary data and organize the information 
in a way that helps leaders understand consumer behaviour trends and patterns. A data analyst must have sound knowledge of r, html, python, JavaScript, sql, c / c++ and so on.

\section{Machine learning engineering}

This discipline includes the creation of systems and machines capable of self-learning without guidance and applying the expertise. A machine learning engineer develops programs that allow computers to perform acts with no clear instructions - such as a self-driving vehicle. Such engineers need to have solid mathematics and/or computer science skills along with java,c++, etc expertise.

\section{Business analysis}

Business analysts plan the infrastructure in collaboration with the development staff, taking into account the business priorities of the company. Accordingly, they evaluate market criteria and development approaches. So, to effectively analyse it, they also need to handle and process a fair amount of data. They must have a clear understanding of xml and sql[12-14].

\section{HOW COMPUTER SCIENCE AND OPERATIONS RESEARCH TECHNIQUES ARE INTEGRATED INTO DATA SCIENCE :}

Data science (DS) and Operations Research (OR) are basically two distinct paradigms. In relation to a given target, OR attempts to provide optimal solutions to the decision problems. DS is concerned with the analysis in the secondary form of large amounts of data. There are, however, several examples of generality. Both paradigms are based on transposition. Many data analytics applications are used in traditional OR areas such as logistics, manufacturing, healthcare, or finance. Moreover, DS and OR are of a multidisciplinary nature. OR has concentrated since its inception in fields such as mathematics, statistics, economics, and computer science. Most of the latest DS textbooks display a heavy bias against one of its founding disciplines, such as database management, machine learning, or stats. The advantage of integration synergies, being multidisciplinary and based on execution, seems to be a logical step for both paradigms. And a growing number of publications of effective approaches at the intersection of DS and OR can be found recently. On the one hand, the performance of the DS process is improved by using advanced optimisation models and methods from OR. On the other hand, efficiency in decision making is improved by increasing traditional OR strategies with DS performance [2, 15, 16].

\section{PREDICTIVE ANALYSIS OF DATA SCIENTISTS IN VARIOUS INDUSTRIES :}

Table 1: Analysis of Data Scientists in various industries.

\begin{tabular}{|l|l|l|}
\hline S.No. & Name of Industry & \multicolumn{1}{c|}{ Characteristics/Predictive analysis } \\
\hline 1. & Retail & $\begin{array}{l}\text { Sixty-two percent of retail respondents believed that insights from } \\
\text { analytics and knowledge offeredcompetitive advantages. }\end{array}$ \\
\hline 2. & $\begin{array}{l}\text { Banking and } \\
\text { Finance }\end{array}$ & $\begin{array}{l}\text { Bank of America uses natural language processing and predictive } \\
\text { analytics to make a tool i.e. Erica to help clients display details } \\
\text { about future bills or display transaction history for decision- } \\
\text { making - conducting business in banks. }\end{array}$ \\
\hline 3. & Medicine & $\begin{array}{l}\text { Big data and analytics will also improve patient services and } \\
\text { reduce waiting times. Medical data is a good example of how } \\
\text { doctors are able to look at vast volumes of data in order to detect } \\
\text { patterns and suggest corrective action. }\end{array}$ \\
\hline 4. & Construction & $\begin{array}{l}\text { Building firms required to complete tasks to material-based } \\
\text { expenses, and everything in between. Big data is now being used } \\
\text { to provide a great way for better decision-making in the } \\
\text { construction industry. }\end{array}$ \\
\hline 5. & $\begin{array}{l}\text { Transportation } \\
\text { kublic transit authorities are now using predictive modelling to } \\
\text { keep things running smothly. Americans made 10.1bn public } \\
\text { transit trips in 2017. The comprehensive data generated by these } \\
\text { trips will enable data scientists to examine these data and ensure } \\
\text { that all obstacles are properly addressed. }\end{array}$ \\
\hline 6. & $\begin{array}{l}\text { Communications, } \\
\text { and }\end{array}$ & $\begin{array}{l}\text { Hadoop Big Data Analytics uses the collection and analysis of data } \\
\text { from its millions of users to make better music recommendations }\end{array}$ \\
\hline
\end{tabular}




\begin{tabular}{|l|l|l|}
\hline & Entertainment & for individual users. \\
\hline 7. & Education & $\begin{array}{l}\text { Big data analytics may also be used to measure teachers' } \\
\text { effectiveness by fine-tuning teachers' performance by evaluating } \\
\text { them against subject matter, student numbers, etc. }\end{array}$ \\
\hline 8. & $\begin{array}{l}\text { Manufacturing and } \\
\text { Natural Resources }\end{array}$ & $\begin{array}{l}\text { Throughout the natural resource sector, it allows decision making } \\
\text { to be assisted by predictive analytics. Data science can be used to } \\
\text { absorb and incorporate these massive data sets to evaluate. }\end{array}$ \\
\hline 9. & Government & $\begin{array}{l}\text { Big Data analytics is used for the efficient processing of medical } \\
\text { information and the identification of false or suspect claims. This } \\
\text { is the use of data analysis tools by the Food and Drug } \\
\text { Administration (FDA) to detect and evaluate disease-linked trends. }\end{array}$ \\
\hline 10. & Energy and Utilities & $\begin{array}{l}\text { Big data analytics can be used to better analyse utility use, which } \\
\text { in turn allows better monitoring of its usefulness and increased } \\
\text { customer reviews. }\end{array}$ \\
\hline 11. & $\begin{array}{l}\text { Outsourcing } \\
\text { Industry }\end{array}$ & $\begin{array}{l}\text { The size of the global data science and analytics outsourcing } \\
\text { market in 2019 was US\$ 3.48 billion and is expected to rise to } \\
\text { US\$ 21.33 billion by 2030 at a CAGR of 27.7 percent. The factors } \\
\text { that drive this growth are shortages of professional labour, and } \\
\text { rapid adoption by various industries. }\end{array}$ \\
\hline
\end{tabular}

The term 'Information Technology' was introduced in 2001, and it took less than two decades to become the subject it is today. Finance was the first industry to understand the benefits of data science when no one was able to scan and analyse vast quantities of data and enable companies to mitigate damage $[17,18,19]$.

\section{OPPORTUNITIES AND CHALLENGES FRAMEWORK FOR DATA SCIENTISTS :}

\subsection{Challenges:}

(i) Investigating the hidden mechanisms of each subpopulation of data which traditionally is not feasible and can even be considered as 'outliers' if the sample size is small.

(ii) Extracting important common characteristics across several subpopulations even though broad variations occur within the individual.

(iii) High dimensionality brings with it noise accumulation, false similarities, and accidental homogeneousness.

(iv) High dimensionality combined with a large sample size creates problems including high computational cost and algorithm instability.

(v) Large collections of Big Data are usually aggregated at various time spots using different methods from multiple sources.

(vi) Dirty data, lack of data science expertise, business dynamics, lack of simple query, unreliable results, outcomes not used by decision-makers, clarification of data science to others and other issues of privacy.

(vii) Small domain expertise and organization lack and the data science team cannot afford to do so[20-21].

\subsection{Opportunities:}

(i) $\mathrm{BI}$ developers are designing and developing strategies to help business users find the information they need to make better business decisions quickly.

(ii) Ensure that data systems are designed for multi-platform software applications and design analytics.

(iii) monitoring the actions of business applications and how they communicate with each other and users.

(iv) Ensure that all business processes operate optimally and are able to facilitate the advancement of emerging technology and system requirements.

(v) work closely with stakeholders, including management and subject matter experts (SMEs), to establish an organization's strategic, analytical, process and IT assets perspective. 
(vi) In order to identify trends that favoura company and help guide strategic business decisions, data scientists would need to be able to analyse vast quantities of complex, raw and processed information.

(vii) Transform and modify broad data sets to match the company's necessary analysis.

(viii) perform batch processing or processing in real time on data obtained and processed.

(ix) Look for new approaches and algorithms to info.

(x) Build funnels for the data and deliver software solutions.

(xi) Interpreting, analysing and reporting statistical, information, such as formulae and market data[20, 22].

\section{DATA SCIENCE AS AN AREA OF SYSTEMATIC STUDY IN UNIVERSITIES :}

- Discover the fundamentals of data mining and the pipeline of data science.

- Describe the key cloud computing principles, models, technologies and facilities, the reasons for moving to this model, and the benefits and disadvantages thereof.

- Build, install, and customize cloud computing applications using cloudcomputing frameworks and libraries, based on software-as-a-service concepts.

- Apply the programming model for MapReduce data analytics and improve its performance by redesigning the system architecture.

- Build Python language programming skills, and some data-related Python libraries.

- Describe the core challenges of cloud deployments in terms of privacy, reliability, and interoperability, including public, corporate, and community cloud deployments.

- Explain and compare offerings from cloud storage providers such as the distributed Amazon S3, Microsoft Azure, OpenStack, and Hadoop file system.

- Learn the basic techniques of software engineering and understand how reproducible and scalable data analysis is made possible.

- Store and access data from a wide range of sources including conventional relational databases, NoSQL data stores and other sources related to the Web.

- Learn how the tools needed for a data science project can be made accessible.

- Know what analyses are feasible provided a particular data set, including both the state of the art of the area and the weaknesses inherent in it.

- Speak fluently with diverse groups within an enterprise to incorporate data analytics approaches, from management to IT manager.

- To make sense of both large and small data sets, using statistical methods, regression techniques and machine learning algorithms [23, 24].

10. DATA SCIENTISTS - DEMAND VS SUPPLY BASED ANALYSIS :

We generated 5 classes, based on the experience of the individuals:

(1) Interns - under 1 year

(2) Juniors - one to two years

(3) Mid-3-5 years

(4) Born - 5-10 years

(5) Veteran-over 10 years 


\section{Number of Tech Skills per Experience Level}

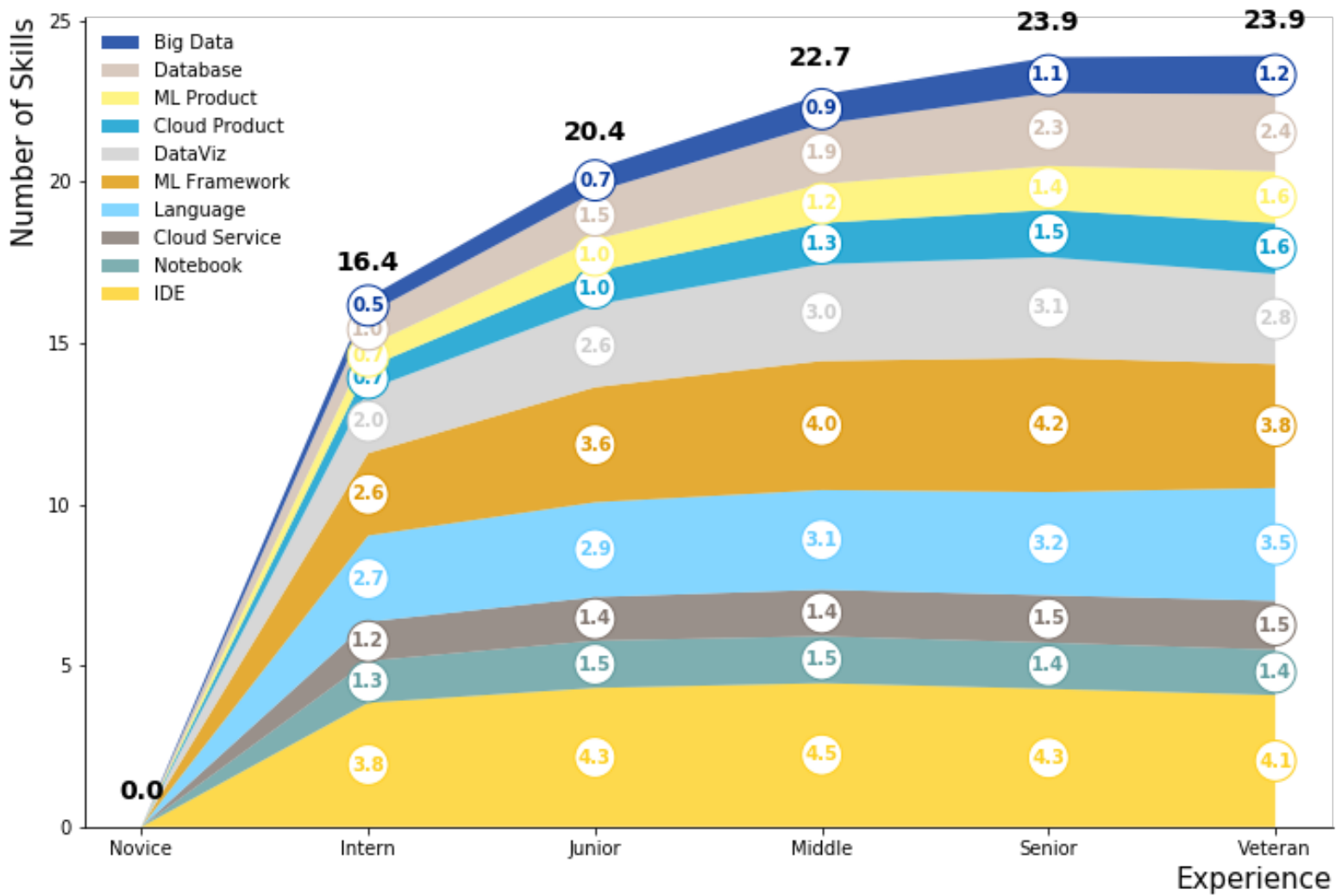

Fig. 2: Basic analysis between Experience and Number of skills [25]

Amount of engineering competencies by the level of experience. The learning curve at the beginning is very steep but hits a Senior Level plateau [25].

\section{SALARY COMPARISION :}

The below table2 is the comparison between salary drawn by the data scientists with ordinary software professionals where it is data engineer, actuary, computer scientist, video game designer, gis specialist, business continuity analyst, data scientists, biostatistician, security management specialist, multimedia animator, UI/UX developer, mathematician, web designer, network/systems support specialist and database architect, etc. It is found that salary will increase more than double times from entry level to senior level. In the analysis, it is compared that data engineers have an edge in salary over other ordinary software professionals in the IT industry at entry level and at senior levels between the years 2001 to 2020 .

Table 2: Comparison of salary drawn by data scientists with ordinary software professionals in IT industry at entry level and at senior levels between the years 2001 to 2020.

\begin{tabular}{|l|l|c|c|}
\hline S.NO. & JOB & $\begin{array}{c}\text { SALARY DRAWN } \\
\text { ENTRY LEVEL } \\
\text { INCREASE Y/Y } \\
(\%)\end{array}$ & $\begin{array}{c}\text { SALARY DRAWN } \\
\text { SENIOR } \\
\text { LEVELINCREASE } \\
\text { Y/Y (\%) }\end{array}$ \\
\hline 1. & Data engineer & 40 & 88 \\
\hline 2. & Actuary & 36 & 75 \\
\hline 3. & Computer scientist & 31 & 62 \\
\hline 4. & Video game designer & 30 & 58 \\
\hline 5. & GIS specialist & 30 & 57 \\
\hline
\end{tabular}




\begin{tabular}{|l|l|l|l|}
\hline 6. & Business continuity planner / analyst & 25 & 49 \\
\hline 7. & Data scientists & 25 & 49 \\
\hline 8. & Biostatistician & 24 & 47 \\
\hline 9. & Security management specialist & 23 & 47 \\
\hline 10. & Multimedia designer / animator & 21 & 46 \\
\hline 11. & UI/UX designer/ developer & 21 & 45 \\
\hline 12. & Mathematician & 19 & 41 \\
\hline 13. & Web designer & 19 & 40 \\
\hline 14. & Network/Systems Support Specialist & 18 & 39 \\
\hline 15. & Database Architect & 18 & 35 \\
\hline
\end{tabular}

Many of this list 's positions share a common emphasis on results. If you're a computer developer, a GIS expert, a data scientist or a database architect, you 're going to spend the majority of your time working with data - selecting it, cleaning it, evaluating it, and drawing from the findings as much as you can. While there are many tools that automate large ranges of data collection and analysis, the practitioners who excel in these positions will require a solid understanding of the underlying concepts [26].

In table3, there is a $15 \%$ hike in year by year from entry level salary to senior level salary of data scientists in the year between 2001 to 2020 where every organization will give very good package to data scientists over edge to other ordinary software professionals in IT industry.

Table 3: Same above things in other industries as data scientists between year 2001 to 2020

\begin{tabular}{|l|l|l|l|}
\hline S.NO. & INDUSTRY NAME & $\begin{array}{c}\text { SALARY DRAWN } \\
\text { ENTRY LEVEL } \\
\text { INCREASE Y/Y (\%) }\end{array}$ & $\begin{array}{c}\text { SALARY DRAWN } \\
\text { SENIOR } \\
\text { LEVELINCREASE Y/Y } \\
\text { (15\% hike in year by } \\
\text { year) }\end{array}$ \\
\hline 1. & IBM Corp: & INR 1,468,040 & INR 1,688,246 \\
\hline 2. & Accenture: & INR 1,986,586 & INR 2,284,573 \\
\hline 3. & JP Morgan Chase and Co: & INR 997,500 & INR 1,147,125 \\
\hline 4. & American Express: & INR $1,350,000$ & INR 1,552,500 \\
\hline 5. & McKinsey and Company: & INR $1,080,000$ & INR $1,242,000$ \\
\hline 6. & Impetus: & INR $1,900,000$ & INR 2,185,000 \\
\hline 7. & Wipro Technology: & INR $1,750,000$ & INR 2,012,500 \\
\hline
\end{tabular}

A data scientist is "a top expert with the experience and enthusiasm to explore big data in the world." As data science is a vast domain, it is necessary that data scientists have a versatile skill set in their profile. Data Science career prospects are shooting right through the roof! When the world turns towards data for all sorts of decision-making, both start-ups and well-established firms such as Cisco, Dell, VMware etc. offer Data Scientist lucrative salaries. The number of Data Science and Analytics job listings is estimated to rise by almost 364,000 listings by 2020, according to Forbes. In addition, the productivity benefits companies analysing data are estimated to be around $\$ 430$ billion by 2020 over their rivals, who are not analysing them. This is quite obvious as you can see from the illustration above. Data scientists are responsible for many business tasks including analytics, designing data products using programming languages such as Java, as well as developing Python or $\mathrm{R}$ visualizations and machine learning algorithms. Therefore, a data scientist's average salary package is Rs 693,637 (IND) or $\$ 91,470$ (US) per year. Furthermore, employers can give you up to $\$ 130,000$ per annum depending on your experience and skill set.

In table4, lucrativeness of data science professionals in terms of salary \& other perks in year 2001 to 2020 where in India and in United States after doing comparison at entry level, middle level and senior level. Everywhere the starting salary package is very good for data scientists and whereas 
other benefits and profit sharing will be there with bonus in India and United States as well on every level of experience of data scientists.

Table 4: Lucrativeness of data science professionals in terms of salary \& other perks in year 2001 to 2020

\section{Data Scientist Salary Based on Experience}

Entry level Data Scientist Salary (IND):

\begin{tabular}{|l|l|}
\hline COMPENSATION & SA \\
\hline Salary & Rs \\
\hline Bonus & Rs \\
\hline Profit Sharing & Rs \\
\hline Total Pay &
\end{tabular}

\begin{tabular}{l} 
SALARY RANGE PER ANNUM \\
Rs 2,87,212 - Rs 11,83,055 \\
\hline Rs $1,998-$ Rs $1,50,145$ \\
\hline Rs 1,000 - Rs 2,50,355 \\
\hline Rs 300.589 - Rs 1,30,333 \\
\hline
\end{tabular}

Entry level Data Scientist Salary (US):

\section{COMPENSATION}

Salary

Bonus

Profit Sharing

Total Pay

Mid-level Data Scientist Salary (IND):

\begin{tabular}{|l|l|}
\hline COMPENSATION & SA \\
\hline Salary & Rs \\
\hline Bonus & Rs \\
\hline Profit Sharing & Rs \\
\hline Total Pay & Rs \\
\hline
\end{tabular}

Total Pay

Mid-level Data Scientist Salary (US):

\begin{tabular}{|l|l|}
\hline COMPENSATION & SALARY RANGE PER ANNUM \\
\hline Salary & $\$ 73,326-\$ 139,120$ \\
\hline Bonus & $\$ 1,872-\$ 18,999$ \\
\hline Profit Sharing & $\$ 2,199-\$ 19,806$ \\
\hline Total Pay & $\$ 76,512-\$ 149,904$ \\
\hline
\end{tabular}

Experienced Data Scientist Salary (IND):

\begin{tabular}{|l|l|}
\hline COMPENSATION & SALARY RANGE PER ANNUM \\
\hline Salary & Rs 9,71,602 - Rs 28,72,457 \\
\hline Bonus & Rs 34,999 - Rs 3,99,999 \\
\hline Profit Sharing & Rs 24,999 \\
\hline Total Pay & Rs 9,62,601 - Rs 28,99,915 \\
\hline
\end{tabular}

Experienced Data Scientist Salary (US):

\begin{tabular}{|l|l|}
\hline COMPENSATION & SALARY RANGE PER ANNUM \\
\hline Salary & $\$ 87,545-\$ 163,358$ \\
\hline Bonus & $\$ 2,500-\$ 21,499$ \\
\hline Profit Sharing & $\$ 19,970$ \\
\hline Total Pay & $\$ 78,450-\$ 1,76,768$ \\
\hline
\end{tabular}


In table5 there is a comparison between top 5 IT \& ITES companies globally in year between 2001 to 2020 other than IT professionals in India and International in different cities geographically salary wise per year.

Table 5: Other IT professionals in 5 top IT \& ITES companies globally in year 2001 to 2020

\begin{tabular}{|l|l|}
\hline COMPANIES & SALARY \\
\hline Microsoft & Rs $15,00,000 / \mathrm{yr}$ \\
\hline IBM & Rs 13,50,000/yr \\
\hline Accenture & Rs 10,55,500/yr \\
\hline Facebook & $\$ 1,35,000 / \mathrm{yr}$ \\
\hline Airbnb & $\$ 1,30,000 / \mathrm{yr}$ \\
\hline Capital One & $\$ 1,06,000 / \mathrm{yr}$ \\
\hline
\end{tabular}

Data Scientist Salary Based on Geography:

\begin{tabular}{|l|l|}
\hline CITY & SALARY \\
\hline Gurgaon & Rs 12,00,000/yr \\
\hline Pune & Rs 7,36,976/yr \\
\hline Mumbai & Rs 7,34,696/yr \\
\hline Mountain View & $\$ 1,24,882 / \mathrm{yr}$ \\
\hline San Francisco & $\$ 1,17,256 / \mathrm{yr}$ \\
\hline Seattle & $\$ 1,16,898 / \mathrm{yr}$ \\
\hline
\end{tabular}

In table6 is the start salary in LPA in and end salary in LPA in the year 2001 to 2020 is also very good in at least 10 IT companies' salary -wise in Indian(6A) and Multinational (6B). In India Quess Corp Ltd and Wipro Ltd. is the best salary wise whereas Internationally Google and Amazon is the best in salary -wise.

Table 6A: OtherIT professionals in 10 top IT companies' salary-wise in India and International in in year 2001 to 2020

\begin{tabular}{|l|l|l|l|}
\hline S.No. & Top IT Companies in India & $\begin{array}{l}\text { Start Salaries } \\
\text { (in Rs. LPA) }\end{array}$ & $\begin{array}{l}\text { End Salaries (in Rs. } \\
\text { LPA) }\end{array}$ \\
\hline 1. & HCL Technologies Ltd & 3 & 8 \\
\hline 2. & Infosys Ltd & 4 & 10 \\
\hline 3. & Larsen \& Toubro Infotech Ltd (LTI) & 5 & 11 \\
\hline 4. & MindTree Ltd & 4 & 13 \\
\hline 5. & Mphasis Ltd & 4.6 & 12 \\
\hline 6. & Oracle Financial Services Software Ltd & 6 & 15 \\
\hline 7. & Quess Corp Ltd & 6.3 & 12 \\
\hline 8. & Tata Consultancy Services Ltd (TCS) & 5 & 13 \\
\hline 9. & Tech Mahindra Ltd & 4 & 10 \\
\hline 10. & Wipro Ltd & 6 & 16 \\
\hline
\end{tabular}

Table 6B: OtherIT professionals in 10 top IT companies' salary-wise in Multinational Companies during the year 2001 to 2020

\begin{tabular}{|l|l|l|l|l|}
\hline Companies & \multicolumn{3}{|l|}{ Software Engineer } & \multicolumn{2}{l|}{ Senior Software Engineer } \\
\hline $\begin{array}{l}\text { Salaries (in } \\
\text { LPA) }\end{array}$ & Start & End & Start & End \\
\hline Google & 4.5 & 38 & 9 & 41 \\
\hline Adobe & 7.4 & 13.5 & 6.85 & 18 \\
\hline Cisco & 4.8 & 28.3 & 6.95 & 29.5 \\
\hline
\end{tabular}

Sachin Kumar, et al, (2020); www.srinivaspublication.com 


\begin{tabular}{|l|l|l|l|l|}
\hline Intel & 6.9 & 29 & 7.1 & 26.2 \\
\hline Microsoft & 3.6 & 26 & 22.3 & 42.8 \\
\hline Juniper & 3.6 & 23 & 13 & 51.6 \\
\hline Amazon & 10.3 & 28 & 15.7 & 40.7 \\
\hline Goldman Sachs & 2.4 & 9.56 & 6.8 & 25.3 \\
\hline
\end{tabular}

In table7 is the start salary in LPA in and end salary in LPA in the year 2001 to 2020 is also very good in at least 10 ITES companies' salary -wise in India and International (7A). In India TCS and Tech Mahindra is the best salary wise whereas Internationally Google and Juniper is the best in salary -wise (7B).

Table 7A: Other IT professionals in at least 10 top IT-Enabled Services(ITES) companies' salarywise in Indian Companies during the year 2001 to 2020

\begin{tabular}{|l|l|l|l|}
\hline S.NO & $\begin{array}{l}\text { TOP IT- ENABLED SERVICES } \\
\text { COMPANIES IN INDIA }\end{array}$ & $\begin{array}{l}\text { Start Salaries (in } \\
\text { Rupees per Annum) }\end{array}$ & $\begin{array}{l}\text { End Salaries (in } \\
\text { Rupees/Annum) }\end{array}$ \\
\hline 1. & TCS - Tata Consultancy Services & $1,63,250$ & $3,45,000$ \\
\hline 2. & $\underline{\text { Infosys }}$ & $1,46,500$ & $3,10,000$ \\
\hline 3. & Wipro & $1,43,250$ & $3,00,000$ \\
\hline 4. & HCL Technologies & $1,41,750$ & $3,10,000$ \\
\hline 5. & Tech Mahindra & $1,41,250$ & $3,12,000$ \\
\hline 6. & Oracle Financial Services & $1,33,500$ & $2,90,000$ \\
\hline 7. & Mindtree & $1,29,000$ & $2,85,000$ \\
\hline 8. & Mphasis & $1,25,750$ & $2,75,000$ \\
\hline 9. & Rolta & $1,23,750$ & $2,70,000$ \\
\hline 10. & Cyient & $1,25,250$ & $2,50,000$ \\
\hline
\end{tabular}

Table 7B: Other IT professionals in at least 10 top IT-Enabled Services (ITES) companies' salarywise in Multinational Companies during the year 2001 to 2020

\begin{tabular}{|l|l|l|l|l|}
\hline Companies & \multicolumn{2}{|l|}{ Project Manager } & \multicolumn{2}{l|}{ Senior Project Manager } \\
\hline $\begin{array}{l}\text { Salaries (in } \\
\text { LPA) }\end{array}$ & Start & End & Start & End \\
\hline Google & 1.5 & 15 & 4 & 27 \\
\hline Adobe & 2.6 & 12 & 1.3 & 10 \\
\hline Cisco & 2.3 & 12.2 & 2.3 & 15 \\
\hline Intel & 2.6 & 14 & 3.1 & 14 \\
\hline Microsoft & 1.6 & 12 & 2.5 & 16 \\
\hline Juniper & 2.3 & 5.6 & 5 & 30 \\
\hline Amazon & 3.3 & 12 & 3.4 & 15 \\
\hline Goldman Sachs & 2.4 & 4.55 & 3.4 & 12 \\
\hline
\end{tabular}

Comparison has been done in different tables to conclude how lucrative Data scientist job during 2001 to 2020 and here it is analysed that lucrativeness between different companies like International \& Indian IT \& other companies have salary, bonus, and profit sharing everywhere in all small to big MNC's and there is a hike of $15 \%$ every year from starting level to end levels. Data scientists earn 5 to 8 times more at entry level and 8 to 10 times more in the exit level.

\section{CONCLUSION :}

The data scientists represent the backbone of data-intensive businesses. Data Scientists aim at extracting, pre-processing and analysing data. By doing so, firms can make better choices. Different companies have their own requirements and are using the data accordingly. In the end, Data Scientist's goal of making businesses grow better.The businesses will follow correct strategies with the decisions and feedback given and tailor themselves for enhanced customer service.Mathematical 
foundations, analytical foundations, statistical foundations, data management and curation, data interpretation and visualization, data modelling and assessment, workflow and reproducibility, communication and coordination, domain-specific considerations and ethical problem solving are required.Ultimately, define data analytics issues that give the greatest benefit to the enterprise, get to know the most appropriate datasets andvariables, work with unstructured data such as video, images, etc, discover new approaches and opportunities by analysing data, cleaning and validating data to ensure precision, completeness and quality, develop and apply models and algorithms For mining bid data, analysing data to identify patterns and trends, communicating visualization findings and other means to stakeholders. Today the demand is more than ever for data scientists and they can earn lucrative salary 5 to 8 times more than many other jobs in the same industry [27-28].

\section{REFERENCES :}

[1] Abbott, M. B. (1986). An introduction to the European hydrological system - System Hydrologique European, 'SHE' 1: history and philosophy of a physically-based distributed modelling system. Journal of Hydrology. 87, 45-59. DOI:https://doi.org/10.1016/0022-1694(86)901149.

[2] Meisel, S. (2009). Integration of Data Mining and Operations Research. In Encyclopaedia of Data Warehousing and Mining, Second Edition (pp. 1046-1052). IGI Global.

[3] Aryal, A., Liao, Y., Nattuthurai, P. and Li, B. (2018). The emerging big data analytics and IoT in supply chain management: a systematic review. Supply Chain Management, 25(2), 141-156. DOI: https://doi.org/10.1108/SCM-03-2018-0149.

[4] Bose, R. (2009). Advanced analytics: opportunities and challenges. Journal of Industrial Management \& Data Systems, 109(2), 155-172. https://doi.org/10.1108/02635570910930073.

[5] Abrahart, R. J. (2012). Two decades of anarchy? Emerging themes and outstanding challenges for neural network river forecasting. Progress in Physical Geography, 36(4), 480-513. DOI:https://doi.org/10.1177/0309133312444943.

[6] Shubhrajyotsna Aithal \& Aithal, P. S. (2018). The Realization Opportunity of Ideal Energy System using Nanotechnology Based Research and Innovations. International Journal of Advanced Trends in Engineering and Technology, 3(2), 1-15. DOI :http://doi.org/10.5281/zenodo.2531876.

[7] Aithal, P. S. \&Shubhrajyotsna Aithal (2019). Building World-Class Universities : Some Insights \& Predictions. International Journal of Management, Technology, and Social Sciences (IJMTS), 4(2), 13-35. DOI:http://doi.org/10.5281/zenodo.3377097.

[8] Akter, S., Wamba, S. F., Gunasekaran, A., Dubey, R., \& Childe, S. J. (2016). How to improve firm performance using big data analytics capability and business strategy alignment?. International Journal of Production Economics, 182, 113-131.

[9] Donoho, D. (2017). 50 years of data science. Journal of Computational and Graphical Statistics, 26(4), 745-766.

[10] Abrahart, R. J., Dawson, C.W., \&Mount, N.J. (2012). Partial derivative sensitivity analysis applied to autoregressive neural network river forecasting. In: Proceedings of the 10th international conference on hydro informatics. 14-18 July 2012. Hamburg: Hamburg University of Technology, pp. 8.

[11] Brandt, P. S. (2016). The emergence of the data science profession (Doctoral dissertation, Columbia University).

[12] Abrahart, R. J. (2011). DAMP: a protocol for contextualising goodness-of-fit statistics in sediment-discharge data-driven modelling. Journal of Hydrology, 409(3-4), 596-611. DOI: https://doi.org/10.1016/j.jhydrol.2011.08.054. 
[13] Ravi, V., \&Kamaruddin, S. (2017, December). Big data analytics enabled smart financial services: Opportunities and challenges. In International Conference on Big Data Analytics (pp. 1539). Springer, Cham.

[14] Krishna Prasad, K., Aithal, P. S. (2017). A Customized and Flexible Ideal Mobile Banking System using 5G Technology. International Journal of Management, Technology, and Social Sciences (IJMTS), 2(1), 25-37. DOI: http://dx.doi.org/10.5281/zenodo.820860.

[15]Shastri, M., Roy, S., \& Mittal, M. (2019). Stock Price Prediction using Artificial Neural Model: An Application of Big Data. EAI Endorsed Transactions on Scalable Information Systems, 6(20), 1-8.

[16] Vaikunth Pai T. \& Aithal, P. S. (2016). Cloud Computing Security Issues - Challenges and Opportunities. International Journal of Management, Technology and Social Sciences (IJMTS), 1(1), 33-42. DOI: http://dx.doi.org/10.5281/zenodo.569920.

[17] Abrahart, R. J., See, L. M.\&Kneale, P. (1999). Applying saliency analysis to artificial neural network rainfall-runoff modelling. In: Proceedings of the 4th conference on Geocomputation, 25-28 July $1999 . \quad$ Fredericksburg, Virginia. Available from: http://www.geocomputation.org/1999/index.htm.

[18] Keerthan Raj (2017). Extracting wealth at the base of the pyramid- study of the business models using ABCD analysis technique. International Journal of Management, Technology, and Social Sciences (IJMTS), 3(1), 59-74.

[19] Bonesso, S., Bruni, E., \&Gerli, F. (2020). How Big Data Creates New Job Opportunities: Skill Profiles of Emerging Professional Roles. In Behavioural Competencies of Digital Professionals (pp. 21-39). Palgrave Pivot, Cham.

[20] Jianqing F., Fang H. \&Han L.(2014). Challenges of Big Data analysis. National Science Review. 293-314. https://doi.org/10.1093/nsr/nwt032.

[21] Pradeep M. D. \&Nornha Sonia D. N. (2018). Study on the Changing landscape of financial in Indian Banking System- Opportunities and Challenges. International Journal of Management, Technology, and Social Sciences (IJMTS), 3(1), 1-10. DOI: http://doi.org/10.5281/zenodo.1147197.

[22]Kaur, P., Sharma, M., \& Mittal, M. (2018). Big data and machine learning based secure healthcare framework. Procedia computer science, 132, 1049-1059.

[23] Anctil, F.\&Lauzon, N. (2004). Generalisation for neural networks through data sampling and training procedures, with applications to stream flow predictions. Hydrology and Earth System Sciences, 8(5), 940-958. DOI:https://doi.org/10.5194/hess-8-940-2004.

[24]Bhatia, M., \& Mittal, M. (2017). Big data \& deep data: minding the challenges. Deep Learning for image processing Applications, 31, 177.

[25] Kache, F.\&Seuring, S. (2017). Challenges and opportunities of digital information at the intersection of Big Data Analytics and supply chain management. International Journal of Operations \& Production Management, 37(1), 10-36. https://doi.org/10.1108/IJOPM-02-2015-0078.

[26] Bonesso, S., Bruni, E., \&Gerli, F. (2020). How Big Data Creates New Job Opportunities: Skill Profiles of Emerging Professional Roles. In Behavioural Competencies of Digital Professionals (pp. 21-39). Palgrave Pivot, Cham.

[27] Arthur, M. (2014). The boundaryless career at 20: where do we stand, and where can we go?.Career Development International. 19(6), 627-640. DOI: https://doi.org/10.1108/CDI-05-2014$\underline{0068}$.

[28]Mittal, M., Balas, V.E., Goyal, L.M. and Kumar, R., (2018), Big Data Processing using Spark in Cloud, 43, (Singapore, Springer Nature Pte Ltd.). 